\section{Portal vein thrombosis despite anticoagulation in a person with diabetes}

\author{
J H Schweigart $M D^{1} \quad$ A Klotsas $M D^{1}$ \\ S Schelenz MD PhD ${ }^{2} \quad K_{\text {Dhatariya }} \mathrm{MD} \mathrm{MRCP}^{1}$
}

J R Soc Med 2005;98:161-163

In a patient with unexplained fever and a potentially hypercoagulable state, a history of sore throat may be of crucial importance.

\section{CASE HISTORY}

A man aged 67 was admitted after six weeks of night sweats, rigors and fatigue. He complained of nausea but there had been no vomiting, abdominal pain or diarrhoea and currently he had no respiratory symptoms. The patient's daughter later revealed that she and her father had experienced mild sore throat and coryzal symptoms eight weeks earlier. The medical history included tuberculosis at age 21, an ischaemic stroke, type 2 diabetes mellitus diagnosed eighteen months ago and poorly controlled on diet $\left(\mathrm{HbA}_{1} \mathrm{C} 9.0 \%\right.$ on admission), congestive heart failure with paroxysmal atrial fibrillation, benign $\mathrm{IgG}$ ( $\kappa)$ paraproteinaemia diagnosed twenty-two months before admission, and stable chronic renal failure secondary to renal vascular disease (creatinine $300 \mu \mathrm{mol} / \mathrm{L}$ ). His drugs on admission were amiodarone, gliclazide, furosemide, atorvastatin, spironolactone, and warfarin. His international normalized ratio (INR) had been 2.92 two months before admission and 3.48 two weeks before admission.

On examination he was apyrexial but sweaty, heart rate $95 / \mathrm{min}$, blood pressure 140/80 $\mathrm{mmHg}$; oxygen saturation was $96 \%$ on room air. He was noted to have very poor mouth and dental hygiene. Initial investigations showed haemoglobin $11.3 \mathrm{~g} / \mathrm{dL}$, white cell count $24.5 \times 10^{9} / \mathrm{L}$ (neutrophils 21.2), erythrocyte sedimentation rate $123 \mathrm{~mm} / \mathrm{h}$, C-reactive protein (CRP) $107 \mathrm{mg} / \mathrm{L}$, INR 2.5, urea $18.9 \mathrm{mmol} / \mathrm{L}$, creatinine $301 \mu \mathrm{mol} / \mathrm{L}$, albumin $30 \mathrm{~g} / \mathrm{L}$, globulin $38 \mathrm{~g} / \mathrm{L}$, alkaline phosphatase $175 \mathrm{U} / \mathrm{L}$, gamma-glutamyltransferase $180 \mathrm{U} / \mathrm{L}$, glucose $14.3 \mathrm{mmol} / \mathrm{L}$. On electrocardiography the only abnormality was longstanding first-degree atrioventricular block; the chest X-ray

Departments of ${ }^{1}$ Diabetes and ${ }^{2}$ Microbiology, Norfolk and Norwich University Hospital NHS Trust, Norwich NR4 7UY, UK

Correspondence to: Dr Ketan Dhatariya, Elsie Bertram Diabetes Centre, Norfolk and Norwich University Hospital NHS Trust, Colney Lane, Norwich NR4 7UY, UK

E-mail: ketan.dhatariya@nnuh.nhs.uk was reported as showing an enlarged heart with evidence of old tuberculosis. Blood and urine cultures taken over the next 4 days were negative. An echocardiogram showed mild impairment of left ventricular function but nothing else abnormal. While he was in hospital his temperature rose to $39.4^{\circ} \mathrm{C}$, but no antibiotics were given because no source of infection was identified. The leukocyte count remained high at $24.1 \times 10^{9} / \mathrm{L}$ and his CRP rose to $130 \mathrm{mg} / \mathrm{L}$. A haematology review (requested because of the benign paraproteinaemia) was unrewarding, and an autoantibody screen for collagen vascular disease was negative. There was no evidence of paroxysmal nocturnal haemoglobinuria, and levels of protein $\mathrm{S}$ and factor $\mathrm{V}$ Leiden were normal. Protein $\mathrm{C}$ levels were not determined because the patient was on warfarin. IgM and IgG anticardiolipin antibody levels were within normal limits. Antithrombin concentrations were normal. We did not investigate the possibility of a mutation in the prothrombin gene. CT of the abdomen and pelvis suggested the presence of a cholangiocarcinoma with tumour or thrombus within the portal vein. Subsequent MRI confirmed extensive portal venous thrombosis but showed no evidence of a cholangiocarcinoma.

During a rigor twelve days after admission another set of blood cultures was taken, and these grew anaerobic Gramnegative bacilli identified as Fusobacterium nucleatum. The bacterium was sensitive to clindamycin, metronidazole and cefotaxime. On intravenous clindamycin $600 \mathrm{mg}$ three times daily the patient swiftly lost all his symptoms. He was discharged on long-term warfarin.

\section{COMMENT}

F. nucleatum has most often been associated with internal jugular venous thrombosis, initially described by Lemierre in 1936. ${ }^{1}$ To our knowledge, only five cases of portal vein thrombosis with $F$. nucleatum or $F$. necrophorum have been reported (Table 1$){ }^{2-6}$

This case is unusual for two reasons. First, the portal vein thrombosis developed despite good anticoagulation. Second, the patient had diabetes. In two of the previous cases the patients had experienced pharyngitis in the weeks beforehand and the bacterium was presumed to have gained entry via the oropharynx; ${ }^{3,6}$ in the other three the gastrointestinal tract was judged the likely route. ${ }^{2,4,5} \mathrm{We}$ assume that our patient's history of sore throat was relevant, though we disovered this only late in the course of his illness, when we quizzed his daughter closely

How might Fusobacterium spp. predispose to thrombosis? One suggested mechanism is thrombogenesis by the lipid A component of the bacterial lipopolysaccharide endotoxin; another is the binding of Fusobacterium to human plasminogen, activating local proteolysis and tissue 

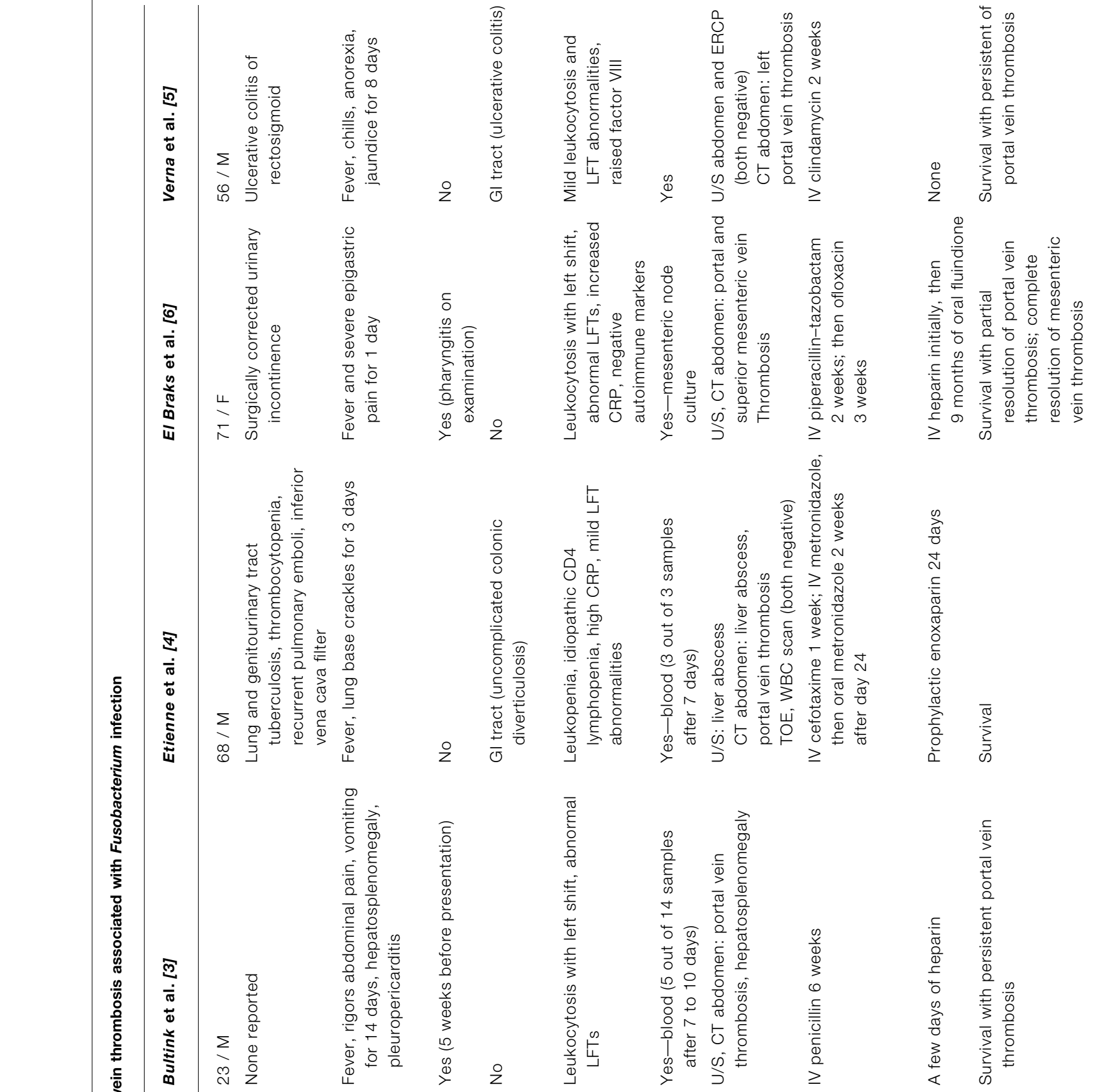

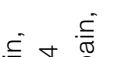
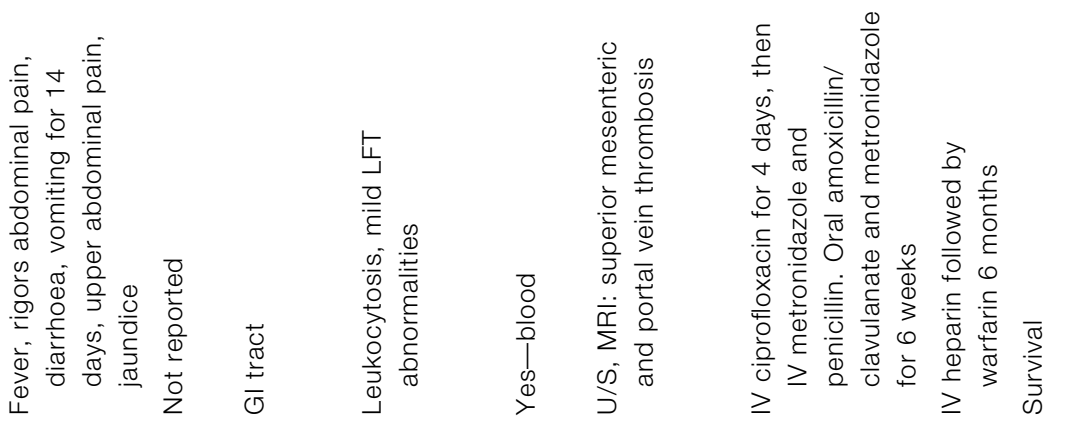

162

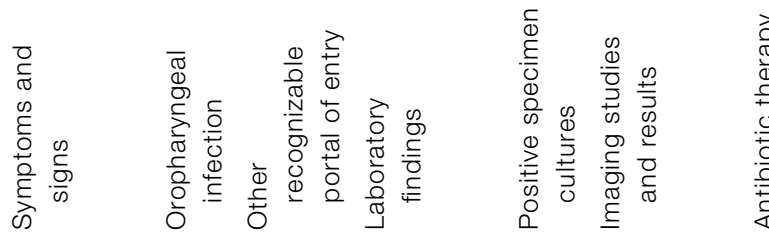

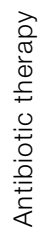

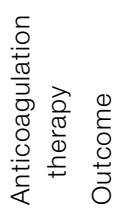


damage. ${ }^{3,4}$ Our patient was well anticoagulated with warfarin and his clotting markers were normal; however, he did have two hypercoagulability factors-namely, diabetes $^{7}$ and a paraproteinaemia. ${ }^{8}$ We conclude that, in a patient such as this with unexplained fever and abdominal symptoms, a history of upper respiratory tract infection should be sought and blood cultures should be taken to detect this fastidious anaerobic organism.

\section{REFERENCES}

1 Lemierre A. On certain septicaemias due to anaerobic organisms. Lancet 1936;i:701-3

2 Soo R, Gosbell I, Gallo J, Pokorny CS. Septic portal vein thrombosis due to Fusobacterium necrophorum. Aust NZ J Med 1999;29:569-70

3 Bultink IE, Dorigo-Zetsma J, Koopman MG, Kuijper EJ. Fusobacterium nucleatum septicemia and portal vein thrombosis. Clin Infect Dis 1999;28:1325-6

4 Etienne M, Gueit I, Abboud P, et al. Fusobacterium nucleatum hepatic abscess with pylephlebitis associated with idiopathic CD4(+) T lymphocytopenia. Clin Infect Dis 2001;32:326-8

5 Verna EC, Larghi A, Faddoul SG, Stein JA, Worman HJ. Portal vein thrombosis associated with Fusobacterium nucleatum septicemia in a patient with ulcerative colitis. J Clin Gastroenterol 2004;38:611-12

6 El Braks R, Harnois F, Boutros N, et al. Mesenteric adenitis and portal vein thrombosis due to Fusobacterium nucleatum. Eur J Gastroenterol Hepatol 2004;16:1063-6

7 Sakkinen PA, Wahl P, Cushman M, Lewis MR, Tracy RP. Clustering of procoagulation, inflammation, and fibrinolysis variables with metabolic factors in insulin resistance syndrome. Am J Epidemiol 2000;152:897907

8 Eby C, Blinder M. Hemostatic complications associated with paraproteinemias. Curr Hematol Rep 2003;2:388-94

\section{Perindopril and pulmonary eosinophilic syndrome}

\section{A P Rochford BSc MRCP ${ }^{1}$ P R Smith MSc MRCP2 S J Khan MRCP $^{1} \quad$ A J G Pearson MB FRCP ${ }^{1}$}

J R Soc Med 2005;98:163-165

Angiotensin converting enzyme (ACE) inhibitors are responsible for several respiratory effects including cough and angioneurotic oedema but an association with pulmonary eosinophilic syndrome is uncommon.

${ }^{1}$ Barnet \& Chase Farm Hospitals NHS Trust, Wellhouse Lane, Barnet, Herts EN5 3DJ; ${ }^{2}$ Department of Infectious Diseases and Microbiology, Institute of Child Health, 30 Guilford Street, London WC1N 1EH, UK

Correspondence to: Dr A P Rochford, Department of Gastroenterology, Barnet \& Chase Farm Hospitals NHS Trust, Thames House, Wellhouse Lane, Barnet EN5 3DJ, UK

E-mail: Andrew.Rochford@ukgateway.net

\section{CASE HISTORY}

A Caucasian woman aged 68 was seen after two weeks of malaise, nausea and sinusitis, for which she had been prescribed clarithromycin. Seven weeks earlier she had been started on perindopril for hypertension, at which time a full blood count was normal. She was also taking co-amilofruse and was using inhaled medications for asthma - fluticasone, begun eighteen months earlier to replace the oral prednisolone she had taken for 15 years, and salbutamol. There was no travel history of note and she kept no household pets. On examination she was apyrexial. No abnormal physical signs were detected - in particular no rash or subcutaneous nodules. Blood pressure was 109/ $80 \mathrm{mmHg}$ and oxygen saturation $97 \%$ on air. Haemoglobin was $10.1 \mathrm{~g} / \mathrm{dL}$, MCV $93 \mathrm{fL}$, neutrophils $9.9 \times 10^{9} / \mathrm{L}$ and the eosinophil count was $13.4 \times 10^{9} / \mathrm{L}$ (52\%). Platelet count and clotting studies were normal; sodium was $128 \mathrm{mmol} / \mathrm{L}$, potassium $4.8 \mathrm{mmol} / \mathrm{L}$, urea $4.5 \mathrm{mmol} / \mathrm{L}$, creatinine $58 \mu \mathrm{mol} / \mathrm{L}$, albumin $31 \mathrm{~g} / \mathrm{L}$, corrected calcium $2.38 \mathrm{mmol} / \mathrm{L}$, C-reactive protein $86 \mathrm{mg} / \mathrm{L}$. There was no active urinary sediment. On sinus radiography the ethmoid and maxillary sinuses were opaque. A chest radiograph showed hyperinflated lungs and a small area of pleural scarring at the left costophrenic angle.

On admission to hospital, perindopril, clarithromycin and the diuretic were withdrawn, and she was continued on a fluticasone inhaler. A low-grade pyrexia developed and on day 6 the eosinophil count had risen to $18.3 \times 10^{9} / \mathrm{L}$ (61\%). CT revealed pulmonary infiltrates with mediastinal lymphadenopathy but no proximal bronchiectasis (Figure 1). Further investigations showed aspergillus precipitins weakly positive at titre $1: 2, \operatorname{IgE} 576 \mathrm{kU} / \mathrm{L}$ (normal $0-81$ ), stool examination negative for ova, cysts and parasites, and

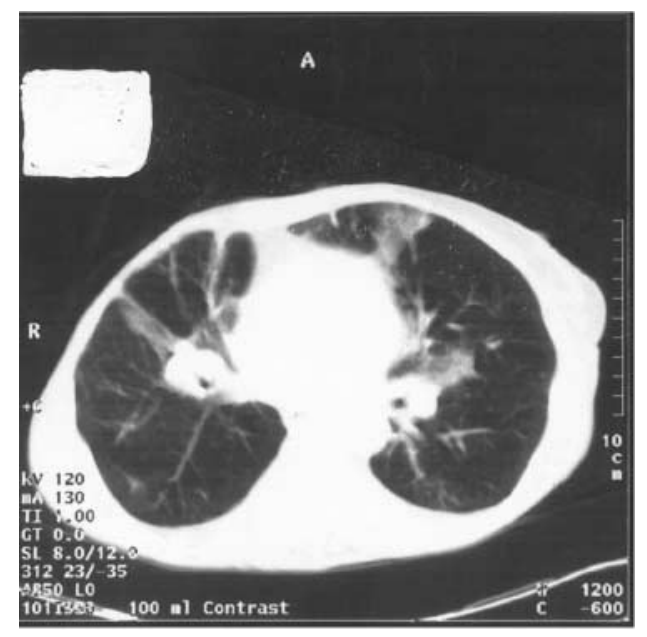

Figure 1 CT of thorax showing prominent peripheral infiltrates in the anterior segments of upper lobes and precarinal lymphadenopathy, an opacity at the right apex and bilateral pleural effusions 